\title{
Hostel, uma proposta de revisão conceitual para a abordagem de futuras pesquisas
}

\author{
Hostels, a conceptual review for the approach to future research
}

\section{Hostel, una propuesta de revisión conceptual para el enfoque de futuras investigaciones}

\author{
Álvaro Augusto Dealcides Silveira Moutinho Bahls
}

Bacharel e Mestre em Turismo \& Hotelaria pela Universidade do Vale do Itajaí - UNIVALI

bolsista Integral CAPES e Editor Executivo do periódico Applied Tourism

alvarobahls@edu.univali.br

\section{Raquel Maria Fontes do Amaral Pereira}

Doutora em Geografia pela Universidade de São Paulo - USP

Docente permanente do curso de Pós-graduação em Turismo \& Hotelaria - Universidade do Vale do Itajaí - UNIVALI

raquelfontes@univali.br

Data de submissão: 08/07/2017 - Data de aceitação: 22/03/2018

\begin{abstract}
Resumo: O objetivo desse estudo é o de propor uma revisão do conceito de hostel, o qual seja mais abrangente do que o encontrado na literatura convencional, buscando agregar aspectos anteriormente desconsiderados. O método de abordagem utilizado foi o materialismo dialético. Primeiramente fora realizada uma revisão da literatura especializada sobre o tema. Em um segundo momento uma pesquisa de campo foi conduzida. O universo de hostels de Florianópolis-SC foi abordado a partir de uma amostragem intencional e não aleatória, mediante entrevistas semiestruturadas. Para extrair os temas essenciais dos depoimentos, buscouse apoio no método de análise de conteúdo, usando como respaldo teórico a $4^{\text {a }}$ Categoria de análise do materialismo dialético, denominada de Essência vs. Aparência. Os aspectos essenciais a esse conceito estão representados nos quadros "Análise dos discursos Superficiais vs. Essenciais", a "Representação gráfica do conceito hostel" e o subproduto "Logo da essência dos hostels". Os novos elementos que foram agregados ao conceito de hostel são aqueles ligados à hospitalidade genuína, pois se constata que esses são, idealmente, a casa de quem recebe e a casa de quem viaja, um local para acolhimento de visitantes e imersão desses na cultura do local visitado, de união e de entendimento entre diferentes povos, de troca de experiências. Essencialmente, os hostels são um local de convergência de pessoas, um local de amizade.
\end{abstract}

Palavras-chave: hostel; hospitalidade; turismo da juventude; conceitualização.

Abstract: The aim of this study is to propose a review of the concept of hostel, which is broader than what is found in the conventional literature, seeking to add aspects previously disregarded. The method used was dialectic materialism. First, a literature review was conducted on the theme. This was followed by a field study. The universe of hostels of Florianópolis, Santa Catarina, was addressed based on an intentional 
non-random sample, through semi-structured interviews. To extract the essential themes from the statements, the method of content analysis was used as support, using as theoretical background the 4th Category of analysis of dialectical materialism, namely, Essence vs. Appearance. The essential aspects of this concept are represented in the frameworks "Analysis of Superficial vs. Essential discourses", "Graphic representation of the concept of hostel" and the subproduct "Graphical representation of the essence of the hostel". The new elements that were added to the concept of the hostel are those linked to genuine hospitality, as it was noted that hostels are, ideally, the homes of those who receive and the home of those traveling, a place of welcome for visitors and their immersion into the culture of the place being visited; a place of harmony and understanding among different peoples, and of Exchange of experiences. Essentially, a hostel is a place where people converge, a place of friendship.

Keywords: hostel; hospitality; youth tourism; conceptualization.

Resumen: El objetivo de este estudio es el de proponer una revisión del concepto de hostel, el cual sea más amplio que el encontrado en la literatura convencional, buscando agregar aspectos anteriormente desconsiderados. El método de abordaje utilizado fue el materialismo dialéctico. Primero fue realizado una revisión de la literatura especializada sobre el tema. En un segundo momento una investigación de campo fue conducida. El universo de hostels de Florianópolis-SC fue abordado a partir de una muestra intencional y no aleatoria, mediante entrevistas semiestructuradas. Para extraer los temas esenciales de las declaraciones, se buscó apoyo en el método de análisis de contenido, usando como respaldo teórico a la $4^{a}$ Categoría de análisis del materialismo dialéctico, denominado Esencia vs. Apariencia. Los aspectos esenciales a este concepto están representados en los cuadros "Análisis de los discursos Superficiales vs. Esenciales", a la "Representación gráfica del concepto hostel" y el subproducto "Logo de la esencia de los hostels". Los nuevos elementos que fueron agregados al concepto de hostel son aquellos ligados a la hospitalidad genuina, pues se constata que estos son, idealmente, la casa de quien recibe y la casa de quien viaja, un lugar para acogimiento de visitantes e inmersión de estos en la cultura del lugar visitado, de unión y de entendimiento entre diferentes pueblos, de intercambios de experiencias. Esencialmente, los hostales son un lugar de convergencia de personas, un lugar de amistad.

Palabras clave: hostel; hospitalidad; turismo de juventud; concepto.

\section{Introdução}

O turismo como um fenômeno social corresponde a uma relação entre pessoas e lugares, sendo essa relação inerente ao ser humano, "cuja essênciaéasuasociabilidade permanente" (Bressan, 2008, p. 07). Suas características estão direta e indissociavelmente ligadas aos acontecimentos socioespaciais, em um dado recorte temporal (Santos, 1979). Pode-se, portanto, considerar o turismo como "uma prática que carrega consigo um grupo de representações sociais" (Panosso Netto, 2010, p. 14) e espaciais, que influenciam diretamente nosso meio ambiente, nossa cultura e, consequentemente, nossas vidas.

A hospitalidade atua como fio condutor dessas representações socioespaciais do fenômeno turístico (Grinover, 2002). O conceito de hospitalidade genuína refere-se ao ato de receber, acolher estranhos sem qualquer expectativa de uma recompensa material (Gotman, 2011;
Montandon, 2011). Ademais, para Derrida (1997), a "hospitalidade é a bandeira de uma verdadeira cruzada contra e intolerância e o racismo" (apud Camargo, 2002, p. 06). E o local da hospitalidade se dá na casa e à mesa do anfitrião (Camargo, 2004; Campos, 2005; Dias, 2002; Grinover, 2002; Krause \& Bahls, 2016; Lashley \& Morrison, 2004; Panosso Netto, 2010).

O objeto desse estudo, os hostels, encontra-se dentro do campo da hospitalidade e dos meios de hospedagem, mas não dentro da hotelaria, pois os hostels foram idealizados com filosofia, características físicas e serviços diferenciados (Coburn, 1950; Giaretta, 2003; Heath, 1962; Trotta, 1978). Nas primeiras viagens, os meios de hospedagem eram casas de pessoas que viviam nas antigas rotas de comércio e a hotelaria se desenvolveu a partir de então (Customer Alliance, 2017; Goeldner, Ritchie \& Mcintosh, 2002). Há quem considere que os hotéis convencionais deram à luz os hostels, sendo esses últimos uma segmentação dos primeiros, uma alternativa 
mais econômica aos hotéis, com serviços e infraestrutura rudimentares (Braga, 2003; Campos, 2005; Garcia, 2004; Vieira \& Cândido, 2003).

No entanto, o caminho traçado pelos albergues da juventude é distinto, pois possui âmago de sua filosofia, os mesmos conceitos da hospitalidade genuína, que dá origem ao primeiro meio de hospedagem dessa tipologia em Altena, Alemanha, em 1912 (Bahls, 2015; Bahls \& Pereira, 2017a, 2017b, 2017c; Coburn, 1950; Heath, 1962; Hostelling International, 2014). Atrelada à sua criação estava a ideia de um local que pudesse abrigar jovens viajantes, sem fins comerciais, promovendo o entendimento entre culturas, a conservação do patrimônio histórico e do meio ambiente (Coburn, 1950; Heath, 1962).

Abrantes (2014) e Volante (2011) corroboram com o problema dessa pesquisa e relatam, de maneira sucinta essa disparidade de abordagens conceituais, demonstrando que o baixo custo das diárias, e por consequência equivocada, o baixo nível de qualidade não são fatores determinantes para o conceito desse meio de hospedagem. Portanto, os hostels devem ser considerados em uma conceptualização singular, fiel à sua idealização, que pode estar mais próxima dos conceitos originais de hospitalidade do que os hotéis convencionais.

Para entender a essência dos hostels e sua relação com o conceito de hospitalidade genuína, é necessário considerar sua gênese (como e por que foram idealizados e criados) para que se possa contextualizá-los na contemporaneidade. A partir desse contexto, problematiza-se que, internacionalmente, os hostels possuem conceitos fiéis à sua gênese bem definidos e são regulados por leis, principalmente no continente europeu e na América do Norte. Nesses locais, possuem características singulares definidas, diferenciando-os claramente dos demais meios de hospedagem. A organização nacional de turismo da Escócia determina critérios básicos para um estabelecimento ser denominado de hostel (Visitscotland, 2012). Países como França, Inglaterra e Alemanha regulamentam as leis e os conceitos para que estabelecimentos sejam intitulados de hostels (The European Consumer Centres' Network, 2009).

Apesar do seu já constatado alto nível de importância social e econômica para o turismo
(Nash, Thyne \& Davies, 2006; UNWTO, 2008, 2010), o MTur não contempla os hostels em sua matriz de classificação de meios de hospedagem, por serem considerados meios de hospedagem coletiva e não individual. Sob o protocolo de número 72550000271201453, foi solicitado ao MTur a legislação vigente sobre os hostels, obtendo-se como resposta a declaração de que "não há legislação no âmbito deste MTur que trate especificamente da questão acerca dos albergues da juventude do Brasil" (Ministério do Turismo, 2014).

Esse distanciamento entre poder público e os hostels estáemdesacordocomumatendênciamundial, visto que o turismo da juventude corresponde a uma parcela representativa do fenômeno turístico e contribui para o desenvolvimento e para a conservação do patrimônio histórico e ambiental (UNWTO, 2010).

Apesar disso, a produção acadêmico-científica sobre esse tema é praticamente embrionária no exterior e inexistente no Brasil, a ponto de não existir uma conceptualização e classificação oficial sobre o mesmo (Bahls, 2015; Bahls \& Pereira, 2018). Além disso parte da literatura especializada sobre esse tema parece desconhecer a gênese (como e por que fora idealizado e criado) ou ignorar a essência desse meio de hospedagem (Bahls \& Pereira, 2018).

Tal realidade põe em evidência a necessidade de mais estudos sobre o tema, para que a academia e o turista percebam os hostels de maneira fiel a suas raízes conceituais e como um meio de hospedagem alternativo viável para todos aqueles que se identificam com a filosofia alberguista.

Assim, o presente artigo tem por objetivo propor uma revisão conceitual sobre os hostels. Revisão essa que componha um conceito mais abrangente do que o encontrado na literatura convencional. Espera-se que, por meio dessa, possa-se agregar aspectos anteriormente desconsiderados, visando contribuir para uma futura classificação do mesmo, junto ao MTur, que faça jus às características essências desse meio de hospedagem.

\section{Marco teórico}

\section{A gênese alberguista}

Em fins do século XIX, a Alemanha encontrava-se em um período de grande expansão 
econômica e tecnológica, liderando a segunda Revolução Industrial, muito embora nem todas as classes sociais se beneficiassem desses avanços. Os jovens, por exemplo, eram usurpados pelos novos meios de produção e suas condições de vida beiravam o desumano (Engles, 2009). Em resposta a essa opressão, originou-se um novo movimento juvenil (o Wandervogel) que se colocava contra uma sociedade que via na natureza e seus povos, algo a ser dominado, moldado à nova regra social e econômica (Coburn, 1950; Heath, 1962; Kennedy, 1998; Laqueur, 1962). Os Wandervogels desejavam ser "integrados como seres humanos [...] pois se consideravam como uma parte crítica da sociedade e não estavam inseridos na condução do seu próprio desenvolvimento. [Propuseram uma] volta à natureza, [as quais eram] tentativas de fugir de uma civilização materialista, sua ênfase era em uma vida simples" (Laqueur, 1962, p. 06).

Foi nesse contexto que o professor de história natural, Richard Schirrmann, integrou os ideais originais dos Wandervogels a um novo meio de hospedagem, buscando aliviar a opressão e a miséria sentidas pelas crianças das grandes cidades, por meio de viagens acadêmicas e lúdicas ao interior do país (Heath, 1962). Ele percebeu que essas viagens poderiam lhes oferecer, além do conhecimento científico, um retorno a uma vida mais simples, em que reinasse o entendimento entre as pessoas, características presentes até hoje em hostels genuínos e no perfil backpacker (Pearce \& Foster, 2007).

Ele percebeu a necessidade de um tipo de acomodação especial para seus estudantes que fosse uma extensão da escola, de suas casas e um local onde eles pudessem mergulhar na cultura do local e compartilhar de experiências entre eles e com as pessoas que os acolhiam (Grassl \& Heath, 1982). Em vez de buscar construir algo novo, preferiam a reutilização do espaço e do patrimônio histórico já existente. Em parceria com o poder público, o castelo de Altena, na cidade homônima na Alemanha, foi renovado e parte dele doado a Schirrmann, em que construiu o primeiro albergue em 1912, "com um design próprio, com dois dormitórios, sala social, uma cozinha, lavabos e banheiros. Grandiosos beliches de madeira harmonizavam com o estilo do castelo" e um "pai" ou "mãe" da casa que pudessem cuidar desses alunos, entretê-los e ensinar sobre o local visitado, ou seja, um anfitrião, um ser acolhedor (Coburn, 1950; Heath, 1962, p. 22).

\section{As raízes da hospitalidade brasileira}

O histórico de apropriação da terra, dos povos, dos bens e dos meios de produção no Brasil, por diversas nações, mas principalmente por Portugal, molda a cultura, a percepção da realidade e a psique brasileira, pois ainda somos associados a Portugal, a "uma tradição longa e viva, bastante viva para nutrir, até hoje, uma alma comum [...] podemos dizer que de lá nos veio a forma atual de nossa cultura; o resto foi matéria que se sujeitou mal ou bem a essa forma" (Holanda, 1995, p. 40). A relação de usurpação - caracterizada sobre o território brasileiro recém descoberto, o qual era utilizado exclusivamente para retirada de bens para sustentar a coroa portuguesa (Fausto, 2013) - dá origem a "um tipo de sociedade que se desenvolveria, em alguns sentidos, quase à margem das congêneres europeias" (Holanda, 1995, p. 31). A relação estritamente comercial entre colônia e coroa portuguesa, estabelecida nos primórdios de nossa história, implanta na psique aspectos que determinam a relação entre o indivíduo hospitaleiro e o estrangeiro (Moraes, 2005).

Para o turismo no Brasil isso tem impacto direto. O primeiro registro hoteleiro acontece na Vila de São Paulo, que começou a servir de base para os tropeiros rumo às minas. Portanto, a gênese da hospitalidade brasileira está voltada diretamente ao estabelecimento de laços comerciais. Apesar de oferecer acomodação, "não se pode dizer que o estabelecimento constituísse uma hospedaria" (Valenzuela, 2013, p. 25), pois, apesar de ser considerado o primeiro hotel do Brasil, fornecia principalmente suprimentos para que desbravadores do interior brasileiro pudessem continuar sua viagem, sem focar seus esforços em acomodação, hospitalidade e/ou cordialidade (Valenzuela, 2013). Mesmo após a vinda da Coroa Portuguesa para o Brasil, no século XIX, ainda assim os relatos mostram locais imundos e a cidade de São Paulo como despreparada para acolher turistas (Fausto, 2013; Trigo, 2002) e, ainda até o final do século XIX, a atitude dos paulistas para com os estrangeiros era de "desconfiança" (Valenzuela, 2013, P. 28). Portanto, o país viveu um período de exploração exclusiva de praticamente 300 anos, suficientes para moldar a psique e a cultura.

O fato de a formação socioespacial brasileira centrar-se inicialmente nas relações mercantis gerou certa dificuldade na implantação de conceitos, tais como o da hospitalidade 
genuína. Portanto, é comum perceber que as demonstrações de hospitalidade no Brasil venham acompanhada de uma relação de interesse, pois os atos primordiais de receber indivíduos eram, e são, tidos como o objetivo de fazer alianças comerciais ou políticas (Assunção, 2012; Castro, Guimarães \& Magalhães, 2013).

\section{O advento dos albergues da juventude no Brasil}

Portanto, conforme Giaretta (2003), somente na década de 1960 o movimento alberguista daria seus primeiros sinais de vida no Brasil. Em virtude da ditadura militar e da dificuldade de viajar quando se é jovem, o primeiro albergue da juventude foi inaugurado somente em meados de 1965, na cidade do Rio de Janeiro, e intitulado de Residência Ramos, com o intuito de "enfrentar" a ditadura imposta à sociedade pelo governo vigente (Giaretta, 2003; Trotta, 1978), similar à filosofia alberguista alemã. Segundo Trotta (1978, p. 17), "os albergues da juventude internacionais existem para ajudar os jovens a viajar, conhecer e amar a natureza e apreciar os valores culturais de pequenas cidades e grandes metrópoles".

O primeiro albergue brasileiro é tardio; são aproximadamente 54 anos de hiato entre a gênese alemã, e "os estrangeiros, em geral, já participavam racionalmente [do movimento alberguista, $e$ os] sulamericanos começaram a aparecer, principalmente da Argentina e Uruguai, onde já existiam albergues há alguns anos" (Trotta, 1978, p. 49). Até então, o incentivo do governo brasileiro aos hostels era inexistente. Somente na década de 1980 o movimento ganha visibilidade, devido ao apoio da EMBRATUR, por meio da criação do Plano Nacional de Albergues da Juventude, o qual contou com uma equipe treinada para supervisionar a criação de novos empreendimentos (Giaretta, 2003). No entanto, a partir de meados da década de 90 , nota-se um contínuo distanciamento entre os albergues e o poder público e a diminuição do número de hostels no país (Giaretta, 2003). Após a virada do século $\mathrm{XX}$, percebe-se sua revitalização com o crescimento do número e o aparecimento de diversas tipologias desse meio de hospedagem (Nash, Thyne \& Davies, 2006), porém de forma desordenada.

A história dos hostels e seu desenvolvimento, principalmente nos países europeus, mostra que há uma relação essencial desse de meio de hospedagem com o acolhimento do ser visitante. A hospitalidade genuína, desprovida de interesse, principalmente comerciais, mostra-se possível de ser vislumbrada com mais frequência nesse tipo de meio de hospedagem do que nos hotéis convencionais. No Brasil, por tratarse de um conceito exógeno, de apropriação tardia, desordenada e equivocada por parte dos empreendedores, dificulta a compreensão e a aceitação desse novo meio de hospedagem. Tanto que, antes do advento dos hostels no Brasil, em 1960, não se tem conhecimento de um meio de hospedagem comercial que apresentasse tais características (Bahls, 2015; Bahls \& Pereira, 2017a, 2017b, 2017c; Bahls \& Pereira, 2018; Giaretta, 2003; Trotta, 1978).

\section{Hostels e suas interfaces conceituais}

Há, na literatura científica tida como tradicional, uma clara deturpação conceitual desse meiode hospedagem. Diversos autores preconizam que os hostels são uma derivação dos hotéis, uma alternativa simplória e econômica aos hotéis convencionais, proporcionando hospedagem com um mínimo de conforto, segurança e higiene a pessoas com poucas condições financeiras em suas viagens (Deus, Delvizio \& Nascimento, 2016; Ferreira, 1975; Ferri \& Ruschmann, 2000; Braga, 2003; Garcia, 2004; Vieira \& Cândido, 2003).

Ferreira (1975) preconiza que os hostels são um tipo de edificação destinada ao alojamento de turistas jovens, de organização simples, porém dotada dos elementos básicos de conforto. Ferri \& Ruschmann (2000) resumem que esse são acomodações de baixo custo, supervisionada, partilhada, geralmente para jovens de idades específicas, oferecendo apenas alojamento básico ou serviços recreacionais e de refeições [grifo nosso]. Em uma mesma linha de interpretação, Braga (2003) coloca os hostels como uma hospedaria modesta [grifo nosso], comparandoos com casas de pouso e pousadas. Ainda dentro dessa mesma perspectiva, Vieira \& Cândido (2003) advogam que esses são estabelecimentos hoteleiros com serviço parciais de hospedagem e de alimentação, que asseguram o mínimo de conforto com higiene. Assim também analisa Garcia (2004), resumindo os hostels como um tipo de hospedagem simples e de baixo custo.

Adicionalmente, Lohmann \& Panosso Netto (2008) já caminham em uma versão conceitual mais ampla e atualizada, e colocam que esse meio de 
hospedagem proporciona acomodações coletivas ou privativas de baixo custo, em que geralmente os hóspedes possuem várias áreas em comum, tais como banheiros, cozinha e sala de estar. Ainda que voltado notadamente para o segmento de mochileiros e do público jovem, os hostels cada vez mais têm ampliado o seu público-alvo e, apesar do baixo custo associado aos albergues, muitos oferecem serviços mais sofisticados, tais como piscinas ou discotecas, entre outros.

No entanto, mesmo que essa definição de Lohmann \& Panosso Netto (2008) seja mais próxima da realidade encontrada, ela peca por não contemplar totalmente as dimensões conceituais dos hostels. Pois, na verdade, é sabido que os hostels foram criados em um local/espaço dotado de contextos histórico, social e econômico únicos e isso faz com que, atualmente, os hostels adquirissem filosofia, características físicas e serviços, também totalmente singulares, voltadas ao acolhimento do ser visitante e sua imersão com o povo e o local visitado (Bahls, 2015; Bahls \& Pereira, 2017a, 2017b, 2017c; Bahls \& Pereira, 2018).

Portanto, pressupõe-se que os hostels estão muito mais próximos do conceito original de hospitalidade do que os hotéis contemporâneos. Os hostels foram idealizados e difundidos como um meio de hospedagem que refletisse a casa e a sala de aula dos jovens de sua época. Visavam, muito além de proporcionar acomodação a baixo custo, colocar as pessoas em contato com a cultura das grandes cidades e com a natureza, propondo um modo mais simples de vida, buscando o entendimento entre as pessoas de diferentes heranças culturais (Bahls, 2015; Costa, Franco \& Hoffmann, 2013; Giaretta, 2003; Heath, 1962; Hostelling International, 2014; Nash, Thyne \& Davies, 2006; Pearce \& Foster, 2007; Trotta, 1978; UNWTO, 2008).

\section{Materialismo dialético}

O método interpretativo utilizado tanto na revisão bibliográfica quanto na elaboração e na aplicação do instrumento de pesquisa, assim como na análise dos resultados obtidos, foi o materialismo dialético. Esse método busca compreender a realidade e analisar as leis sociológicas, muitas vezes contraditórias e antagônicas, que caracterizam a vida social (Glaser, 2008; Pinto, 1979), descrevendo, analisando e criticando a evolução histórica e a sociedade, no decorrer do desenvolvimento da humanidade (Robaina, 2013).

Portanto, procura-se encontrar "explicações coerentes, lógicas e racionais para os fenômenos da natureza, da sociedade e do pensamento", das quais o conceito de alienação é um dos importantes constituintes para a compreensão da realidade (Marx \& Engels, 1998). Assim sendo, pode-se determinar, "através do enfoque dialético da realidade, $[q u e]$ o materialismo mostra como se transfora a matéria e como se realiza a passagem das formas inferiores às superiores" (Triviños, 1987, p. 51). Nesse caso, as formas inferiores, por exemplo, um segmento alienado de uma determinada sociedade, ao se afastar da forma e local superiores, dão origem a reações sociais, por vezes libertários, modificando o espaço e a sociedade (Lefebvre, 2009; Marx \& Engels, 1998).

Finalmente, deve-se considerar que antagônica a essa realidade materialista, por vezes conflitante, existe a possibilidade de nascimento de um pensamento cooperativista (Costa, Franco, \& Hoffmann, 2013), essencialmente idealista, em alguns casos até mesmo romântico, de cunho social, como o existente na própria filosofia alberguista (Heath, 1962).

\section{Metodologia}

O estudo caracteriza-se por uma abordagem qualitativa e exploratória. É exploratório, pois possui caráter inovador e busca, acima de tudo, "aprimorar ideias e descobrir intuições" (Dencker, 2007, p. 151), visando oferecer maior familiaridade com o problema em questão, tornálo mais explícito ou ainda construindo hipóteses sobre o mesmo (Gerhardt \& Silveira, 2009). Este tipo de abordagem procura responder a:

... questões particulares [em um] nível de realidade que não pode ser quantificado [ou seja] ela trabalha com o universo de significados, motivos aspirações, crenças, valores, atitudes, o que corresponde a um espaço mais profundo das relações, dos processos e dos fenômenos que não podem ser reduzidos à operacionalização de variáveis (Marconi \&Lakatos, 2003, p. 271).

A hospitalidade, no turismo, pode receber conotações qualitativas, se se considerar o turismo como fenômeno social, como é o caso desse estudo. A pesquisa qualitativa não foca sua essência na representatividade numérica, mas, sim, na 
subjetividade dos aspectos analisados, procurando aprofundar a compreensão de um grupo social ou de uma organização. Preocupa-se, portanto, com aspectos da realidade que não podem ser quantificados, focando-se na compreensão e na explicação da dinâmica das relações sociais, trabalhando com o universo de significados, motivos, aspirações, crenças, valores e atitudes, que correspondem a um espaço mais profundo das relações, dos processos e dos fenômenos que não podem ser reduzidos à operacionalização de variáveis (Deslauriers, 1991; Gerhardt \& Silveira, 2009; Minayo, 2001).

Para a pesquisa de campo foram usadas entrevistas semiestruturadas, ideais para esse tipo de abordagem, pois além de simplesmente compilarem informação, permitem a observação participante do entrevistador (Sin, 2003). Essas entrevistas, formuladas de forma mais aberta, permitem ao entrevistado dissertar, pois "as questões são organizadas para explorar um tema, aprofundá-lo, descrever processos, compreender o passado vivido do entrevistado, [...] padrões de comportamento, reunir elementos para a compreensão de uma situação ou de um problema" (Leal, 2011, p. 54).

Para extrair os temas essenciais dos depoimentos, foi usado o método de análise de conteúdo. Esse constitui "um conjunto de técnicas utilizadas na análise de dados qualitativos que proporciona um olhar multifacetado sobre a totalidade dos dados recolhidos" (Campos, 2004, p. 611). O método salienta o caráter social do conteúdo analisado, com o objetivo de produzir inferências dentro do contexto social, de forma objetiva (Bauer \& Gaskell, 2002; Silva \& Fossá, 2013). Devido à imensa diversidade de suas técnicas e aproximações terminológicas, adotaram-se nesse estudo as etapas da técnica propostas por Bardin (2009). Resumidamente, a análise de conteúdo do referido autor compreende às seguintes fases:

1) Leitura geral do material coletado (entrevistas e documentos); 2) Codificação para formulação de categorias de análise, utilizando o quadro referencial teórico; 3) Recorte do material, em unidades de registro (palavras, frases, parágrafos) comparáveis e com o mesmo conteúdo semântico; 4) Estabelecimento de categorias que se diferenciam, tematicamente, nas unidades de registro (passagem de dados brutos para dados organizados). [...] 5) agrupamento das unidades de registro em categorias comuns; 6) agrupamento progressivo das categorias (iniciais intermediárias - finais); 7) inferência e interpretação, respaldadas no referencial teórico [nesse caso o materialismo dialético] (Silva \& Fossá, 2013, p. 04).

Já as categorias de análise do materialismo dialético "possuem a função de intérpretes [da realidade] e de indicadoras de uma estratégia [social, sendo] o instrumento metodológico da dialética para analisar os fenômenos da sociedade" (Cury, 1990, p. 21).

Essas categorias, sob a abordagem de Kosik (2002), Richardson (2008) e Taniguti (2010), são: $1^{\text {a }}$ Categoria - geral/particular/individual: todo fenômeno do mundo que nos rodeia possui características específicas, próprias; $2^{a}$ Categoria - causa/efeito: causa é o fenômeno que produz outro fenômeno. Efeito é o resultado

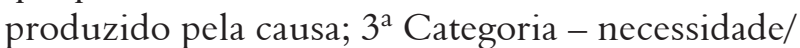
casualidade: necessidade é o que deve ocorrer em determinadas condições. Casualidade é o que pode ocorrer ou não; $4^{a}$ Categoria - essência/aparência: ao conhecer um objeto ou fenômeno, o que primeiro se constatou são seus aspectos exteriores [aparência]. Após um estudo mais aprofundado, se está em condições de compreender sua essência. Aparência é a parte superficial, mutável de um fenômeno ou da realidade objetiva. É uma forma de expressão da essência e depende dela. A essência é a parte mais profunda e relativamente estável do fenômeno ou da realidade objetiva. Está oculta debaixo da superfície de aparências; $5^{a}$ Categoria - conteúdo/forma: o conteúdo é o conjunto de elementos, interações e mudanças características de um fenômeno. Forma é o sistema estável de relações entre elementos de um objeto ou fenômeno; $6{ }^{a}$ Categoria - possibilidade/ realidade: possibilidade é o que pode surgir pela uniformidade do desenvolvimento, mas que ainda não aconteceu. Realidade é o que já aconteceu.

A categoria escolhida para análise, nesse estudo, foi a denominada de "essência/aparência", pois essas categorias estão inter-relacionadas e, portanto, a "análise de um objeto ou fenômeno não precisa ser feita com todas, basta escolher uma delas" (Richardson, 2008, p. 50). No conteúdo das entrevistas analisadas, foi definido como essencial: 1) aquilo que foi determinado como essencial 
na gênese dos hostels; 2) aquilo que é perene, existindo desde o início até a contemporaneidade; 3) aquilo que foi ressaltado como essencial pelo entrevistado, mesmo que não conste na gênese.

Ressalta-se, porém, que não foram utilizados indicadores de essência/aparência preestabelecidos. Os indicadores foram eleitos após a análise. Essa modificação metodológica permite o surgimento de indicadores que não seriam contemplados pelo analisador, favorecendo uma maior abrangência de conteúdo a ser analisado e imparcialidade do mesmo (Leal, 2011). Posteriormente, os termos essenciais do discurso foram agrupados em 5 categorias/indicadores: hospitalidade, serviços, estrutura física, perfil backpacker e outros.

Contemplou-se o universo de hostels independentes de Florianópolis, Santa Catarina, com um total de 28 estabelecimentos. Para esse levantamento utilizou-se o site www.hostelworld. com, considerado o maior mecanismo de reservas para esse meio de hospedagem e o "site mais confiável para reservas on-line em Hostels" (Web Reservations International, 2013). No Brasil há cerca de 114 estabelecimentos no Cadastro dos Prestadores de Serviços Turísticos - CADASTUR (Libório \& Oliveira, 2014). Segundo o Hostelworld, 2014), somente na cidade do Rio de Janeiro existem 130 hostels ativos. Portanto, o número mercadológico representa a realidade deste segmento que, no momento, se encontra à margem das fiscalizações do MTur.

A escolha pela amostra de mercado em detrimento da elaborada pelo CADASTUR visa eliminar um problema frequente da pesquisa em turismo, cujas estatísticas nem sempre são atualizadas, fazendo com que o universo seja estimado em dados do passado (Dencker, 2007). Delimitou-se Florianópolis (SC) como local de pesquisa, pois esse meio de hospedagem em SC é relativamente mais recente do que nos demais destinos. A carência de estudos sobre esse tema em nível nacional é preocupante e fora do eixo Rio-São Paulo é mais carente ainda. Portanto, os destinos hosteleiros brasileiros marginalizados clamam por pesquisas científicas sobre o tema.

Os participantes foram determinados a partir da amostragem intencional e não aleatória. Todo o universo foi abordado pessoalmente e convidado a participar da pesquisa. Essa técnica define que todos os componentes do universo devem ter igual oportunidade de participar da amostra (Richardson, 2008). A amostra obtida de quinze (15) respondentes é qualitativamente representativa $-53,57 \%$ do universo (Dencker, 2007; Leal, 2011; Marconi \& Lakatos, 2003; Martins, 2009). Essa amostra é composta de respondentes proprietários e/ou gerentes dos hostels em questão. As entrevistas foram realizadas no segundo semestre de 2015.

Adicionalmente, como um subproduto da análise de conteúdo das entrevistas, foi criado um logo, uma forma de representar visualmente, de maneira mais simples, a essência dos hostels. Para tanto, foi usada a representação gráfica chamada de nuvem de palavras, que consiste em uma representação visual de dados de texto, normalmente usada para descrever metadados de palavras-chave em sites ou para visualizar, de uma forma facilitada, um texto livre. Ainda pode ser considerada uma lista hierarquizada visualmente, uma forma de apresentar os itens de conteúdo de um texto extenso (Halvey \& Keane, 2007).

\section{Resultados}

\section{A essência dos hostels na perspectiva dos empreendedores de Florianópolis}

Por tratar-se de um meio de hospedagem extremamente jovem, procurou-se descobrir e relatar, concomitante à história dos estabelecimentos, a história pessoal dos entrevistados, pois se acredita que a formação pessoal de cada indivíduo determina sua personalidade e vários outros aspectos materiais de sua vida, inclusive seu perfil profissional, como a escolha pela gestão de um meio de hospedagem como o hostel.

Para formular um conceito de hostel, analisouse a essência dessas entrevistas, visto que os conceitos nada mais são, em sua forma mais abstrata, do que uma pretensão de encapsular a essência de um fenômeno e/ou objeto por meio da comunicação verbal, escrita à ciência humana. Os quadros conceituais são uma forma de ilustrar essa essência, pois propõem trazer à tona uma mudança de consciência, uma aceitação ao novo ou ao desconhecido (Zopiatis \& Constanti, 2012).

Finalmente, um conceito do meio de hospedagem intitulado de hostel deve representar as características aparentes, mas principalmente suas características essenciais. As palavras consideradas 
como chaves do discurso de cada respondente foram divididas entre esses dois grupos. Assim, permite-se determinar os aspectos superficiais do objeto de estudo, como as características essenciais dos hostels, ilustradas resumidamente no quadro 1 .

De acordo com os depoimentos dos entrevistados, podem-se deduzir algumas afirmações quanto à essência dos hostels em Florianópolis. Esses aspectos devem ser considerados (juntamente à história desse meio de hospedagem no Brasil e na Alemanha, local de sua gênese, e ao panorama do universo de hostels brasileiros) quando se contemplar a criação de um conceito desse meio de hospedagem.

Portanto, a essência dos hostels reside, de acordo com os entrevistados, na hospitalidade, e essa pode ser traduzida como uma relação de maior proximidade entre ser acolhedor e ser acolhido, como fora detectado em sua gênese. Esse elo pode ser tão íntimo que a amizade brota dessa interação em alguns casos. O hostel pode ser considerado como uma casa longe de casa para o ser acolhido e, em alguns casos é, realmente, a casa do ser acolhedor, cujos seus integrantes compõem uma grande família, família essa que era o intuito do criador dos hostels (Richard Schirrmann), perdurando até hoje na filosofia alberguista.

O ser acolhido, devido à informalidade do local e das relações pessoais realizadas nesse último, se sente seguro e à vontade, confortável não só fisicamente, mas psicologicamente, pois o ser acolhido é visto como seu par, ambos podem ser quem realmente querem ser e não uma interpretação de papéis como cliente e empresário. A hospitalidade possui na figura do recepcionista sua personificação, é por meio dele que as ideias, o conceito de hospitalidade se materializam, pois um hostel é composto de pessoas e de suas interações. O ser acolhedor é a essência desse estabelecimento, pois devido ao seu passado como viajante, ele projeta sua própria essência pessoal nos seres acolhidos que adentram seu recinto.

Desde sua origem, o idealizador e criador dos hostels preconizava que a figura do Hausvater ou da Hausmutter (pessoa que residia no albergue, ou muito próximo a este, e conhece muito bem a região) era essencial para esse meio de hospedagem. Essa pessoa "cuidava da limpeza e, além de providenciar as refeições noturnas, também entretinha os hóspedes e lhes ensinava sobre a cultura local, exercendo o papel de anfitrião, mais tarde concebido na figura do recepcionista" (Bahls, 2015, p. 75).

Há, além da relação entre hóspede e anfitrião, uma relação de simbiose entre ambos. O relacionamento entre essas partes, traduzido aqui como hospitalidade, reside no âmago da essência de um hostel. Esse relacionamento é traduzido em uma interação entre essas partes, que possui o intuito de promover a união pessoal e do grupo, união essa que perdura até os dias de hoje na filosofia dos albergues da juventude. Quando essa relação produz uma sinergia, a hospitalidade pode ser materializada em sua forma mais pura e genuína, em que o pagamento monetário por serviços é substituído por outras formas de remuneração, como uma troca de experiências e reconhecimento pessoal. Verdadeiras amizades são concretizadas e perduram além do período de estadia do hóspede no estabelecimento.

De uma maneira geral, o serviço tido como essencial, do ponto de vista dos empreendedores hosteleiros de Florianópolis, é aquele muito próximo ao conceito de hospitalidade visto no parágrafo anterior, o serviço de acolhimento, de informação e de interação entre as pessoas. O papel do recepcionista é o de "abraçar" o hóspede, fazer com que ele se sinta em casa, não só “à vontade", mas que conheça o lugar da perspectiva de um morador local, para que possa desfrutá-lo da melhor maneira possível durante sua estadia. Especificamente, o recepcionista promove essa interação de diversas formas, no caso de Florianópolis, as mais comuns são a realização de trilhas ou passeios de bicicleta em meio à natureza, atividade essa que reside na gênese dos Wandervogels e dos albergues da juventude, sendo essa atividade a geradora desse meio de hospedagem no início do século XX. Outro serviço tido como essencial é o café da manhã. Além de prover o suprimento alimentar e satisfazer as necessidades biológicas pessoais, é nesse ato que as pessoas interagem pela primeira vez no dia, traçam planos de visitar locais fora do albergue, é onde nascem novos elos pessoais.

Os jantares comunitários complementam o serviço de café da manhã. São esses eventos que reúnem as pessoas ao final do dia, é ali que são fortalecidos os elos estabelecidos no decorrer do dia, nas atividades diversas realizadas pelo grupo de hóspedes e, muitas vezes, com a presença do recepcionista. A congregação em volta da mesa, tendo a gastronomia como pano de fundo, é 


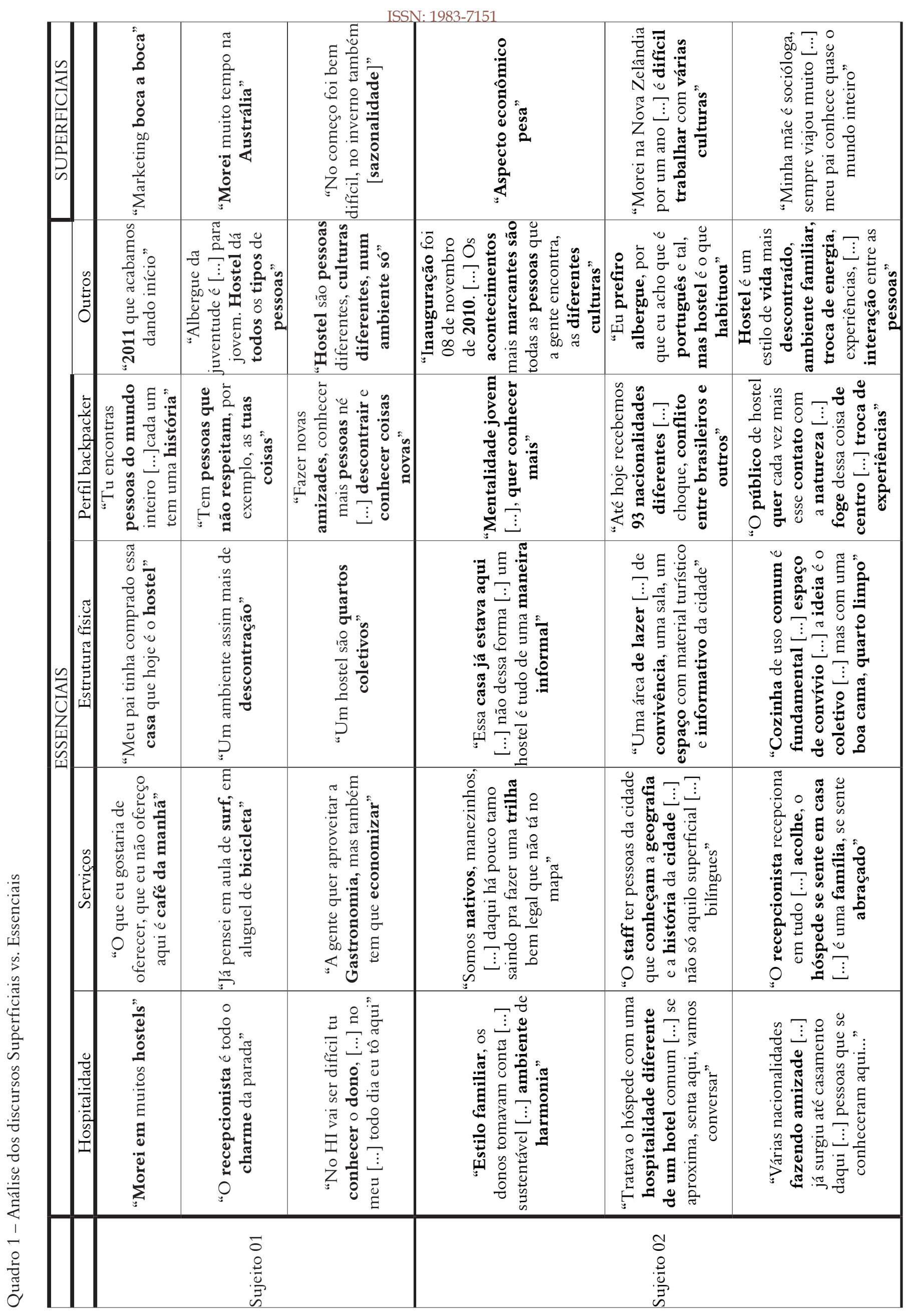

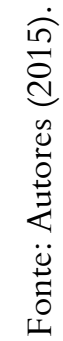


uma atividade hospitaleira recorrente à gênese da civilização humana. A limpeza é outro serviço essencial e vista como uma área de grande preocupação pelos hosteleiros. Outros serviços essenciais são as atividades de lazer em grupo, como as aulas de surfe, devido à disponibilidade e à popularidade do esporte em toda a ilha de Santa Catarina. Outro serviço oferecido é a internet, disponibilizada em forma de Wi-Fi, devido ao perfil do viajante mochileiro, do desejo e da necessidade de estar sempre conectado ao mundo, compartilhando suas experiências em praticamente tempo real e planejando seus próximos passos.

A diversidade cultural é um fator tido como essencial, favorecendo o desenvolvimento pessoal dos próprios administradores, os quais entram em contato com diversas culturas no seu ambiente de trabalho. Os hosteleiros também reconhecem que esse fator é um dos de maior apelo à imagem desse meio de hospedagem para o seu público-alvo. Os backpackers procuram, além de um local que seja original ao destino visitado, por um ambiente culturalmente diversificado, onde possam trocar experiências com os hóspedes de onde se encontram.

As áreas físicas essenciais são todas aquelas consideradas como áreas comunitárias ou áreas de convivência. Dentre elas as mais mencionadas são os quartos coletivos com banheiro dentro desses, as cozinhas comunitárias, salas de jogos, estar e/ ou TV, e os espaços gastronômicos (como áreas de churrasqueira, bares/pubs, lanchonetes e/ou restaurantes). As áreas sociais e de lazer externas, como varandas, piscinas, decks e redes, estão entre as principais, de acordo com os hosteleiros, pois o clima de Florianópolis favorece a interação pessoal em espaços abertos. Os espaços informativos (de leitura, informação sobre a cidade e outros destinos turísticos), incluindo-se aqui a recepção, completam as áreas físicas essenciais dos hostels do município.

\section{Hostel, um conceito em formação}

Reunindo todo o arcabouço teórico e os resultados da pesquisa de campo, chega-se à proposta de um conceito de maior abrangência do meio de hospedagem denominado de hostel do que o atual encontrado na literatura convencional.

Pode-se constatar que os hostels se apoiam em uma grande base matricial (1) da qual nascem os três principais pilares de sustentação (2) para esse conceito, a hospitalidade (representada na figura do recepcionista); infraestrutura e serviços. A base dessa matriz está fundada na sua gênese históricasocial e na relação entre homem e território, a qual não pode ser ignorada, já que nela se encontram as interações entre o homem e o espaço, dando início às nossas representações físicas e culturais e, consequentemente, a esse meio de hospedagem.

Isso, por conseguinte, gera uma filosofia, que se expressa em suas características físicas e nos serviços únicos. É essencial saber que a hospitalidade (2) permeia esta filosofia e age como fio condutor de todas as relações entre visitante e meio de hospedagem. A hospitalidade propõe, entre outros princípios, a união entre pessoas, povos e culturas, o acolhimento honesto de desconhecidos, oferecendo-lhes auxílio e amparo e propiciando a troca de conhecimento entre anfitrião e visitante. Essa filosofia de hospitalidade, que se traduz no tipo de infraestrutura e serviços que serão oferecidos aos hóspedes, acaba por definir uma nova relação entre sujeito acolhedor e sujeito acolhido (3). Essa relação permite ao ser acolhido se aproximar mais facilmente e profundamente na cultura local e de outros viajantes que se encontram no estabelecimento. Além disso, o caminho dessa interação também é inverso (4). O sujeito acolhedor, geralmente representado na figura do recepcionista, participa de atividades e eventos, intra/extra hostel, junto com o hóspede. Inevitavelmente ele acaba por absorver a cultura de seus hóspedes, aprende com eles, interagindo na sua própria viagem, tornandose parte da experiência de vida de outras pessoas, enquanto cresce na sua própria.

A principal contribuição dos resultados dessa pesquisa, tanto da parte bibliográfica quanto dos resultados da pesquisa empírica, concentra-se nessa relação simbiótica, entre hóspede e anfitrião, em que se acaba obtendo, em alguns casos, uma modificação na própria estrutura física do local e nos serviços, com a influência direta do hóspede (5), mas principalmente uma modificação na percepção de hospitalidade entre os dois sujeitos (ser acolhedor e ser acolhido). No caso dos hostels, os hóspedes, por vezes, acabam interagindo diretamente nessa transformação. Como relatado pelos entrevistados, devido ao cunho comunitário dos hostels, os hóspedes podem ajudar desde a limpeza a pequenas reformas na estrutura física, como em um desenho/pintura interno de uma sala de estar, que acaba por decorar o local. Nos serviços, essa simbiose é ainda maior. Diversos 
passeios e eventos gastronômicos são organizados pelos próprios hóspedes, quando se sentem à vontade e dispostos para tanto, e o anfitrião participa dessas atividades como "convidado" do grupo. Ele deixa o papel de "chefe" do recinto e passa a ser mais um indivíduo dentro do grupo de viajantes. Essa relação de simbiose reside na essência do entendimento do conceito de hospitalidade, de reconhecer no outro seu valor, de comunhão cultural e pessoal.

A contribuição original e inédita mais relevante dessa pesquisa reside no fato de que (tanto a revisão da literatura quanto os dados empíricos) mostra que, quando o conceito de hostel é abordado conforme o que é demonstrado e proposto por esse estudo, ambos os sujeitos/atores desse fenômeno turístico passam a se perceber como seres humanos participantes de uma relação complexa e profunda, muitas vezes extenuante e até mesmo ríspida em alguns momentos (fato esse que está na essência das relações de hospitalidade genuína, em que a inospitalidade acompanha o seu oposto frequentemente - e que se comprova com a revisão do marco teórico sobre materialismo dialético), porém gratificante.

Essa relação única acaba por influenciar diretamente o território turístico (6), pois o ser acolhedor que fica absorve parte do ser acolhido que parte. Ele se modifica a cada hóspede e acaba por modificar seu espaço, sua casa. Cada viajante leva consigo uma parte daquele local, daquela pessoa. As ações dos hosteleiros perante seu local de moradia, seu local turístico, serão direcionadas à promoção e à conservação desse último, pois no orgulho da partilha desse patrimônio reside o cuidado com o mesmo. O visitante completa seu ciclo de visitação, mas as memórias e as amizades perduram para sempre.

As características desconsideradas pela literatura convencional sobre hostels se referem, essencialmente, ao relacionamento entre "ser acolhido" e "ser acolhedor" (visitante e visitado). As relações interpessoais estão acima de outras características físicas e serviços convencionais abordados pela literatura clássica. Outra característica essencial, também desconsiderada pela literatura convencional, é que a relação que estes locais, e as pessoas que os ocupam, está muito mais próxima do conceito de hospitalidade genuína do que nos hotéis convencionais, por exemplo. Em poucas palavras, hostel é, acima de tudo, sobre as pessoas e seus lugares (Figura 1).

Além da Figura 1 (que expressa um conceito mais amplo de hostel, incluindo suas características essenciais, anteriormente desconsideradas pela

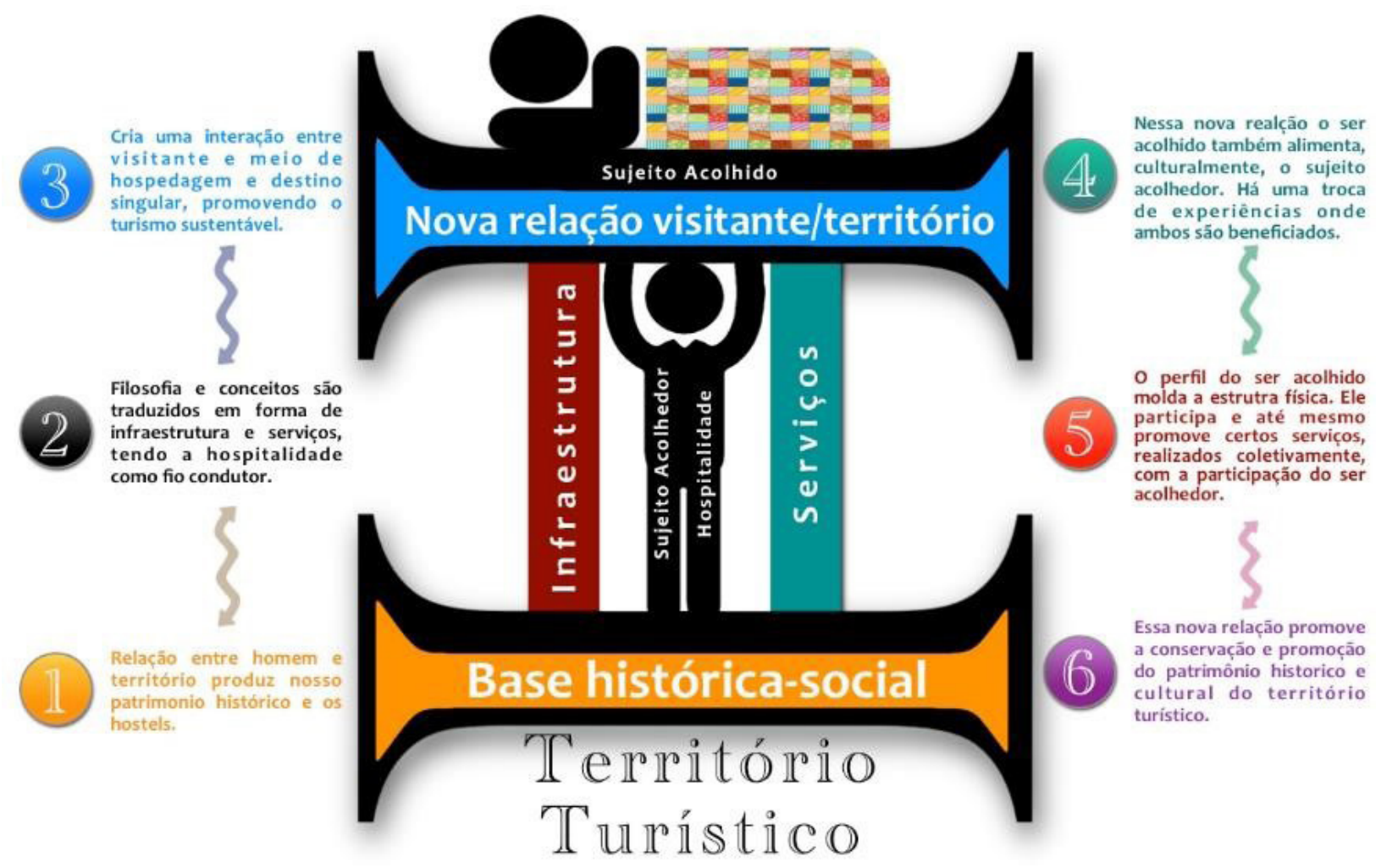

Figura 1 - Representação gráfica do conceito hostel Fonte: Elaborada pelo autor (2015). 
literatura convencional), buscou-se criar uma segunda representação visual do conceito de hostel, como um subproduto, em forma de um possível logo desse meio de hospedagem capaz de traduzir a essência do mesmo, com base na análise de conteúdo do discurso dos entrevistados de forma mais simples (Figura 2). O logo foi idealizado a partir da letra " $\mathrm{H}$ ", inicial da palavra Hostel, incorporando as palavras ditas com maior frequência pelos entrevistados. O peso de cada palavra está refletido no tamanho da mesma.

\section{Considerações finais}

O turismo da juventude é de extrema importância econômica e social. No entanto, a pesquisa científica sobre esse tema é embrionária e carece de aprofundamento. Essa pesquisa não pretende determinar o conceito de hostel, mas sim propor uma revisão e criar um esboço dos conceitos representativos desse meio de hospedagem original e fiel às suas raízes.

Em retrospectiva, o primeiro aspecto que se deve considerar para a elaboração desse conceito é a carga histórica que esse meio de hospedagem possui, pois é diferenciado e apresenta em sua gênese ideológica aspectos que determinaram claramente suas características atuais. Em um segundo momento, deve-se considerar a clara

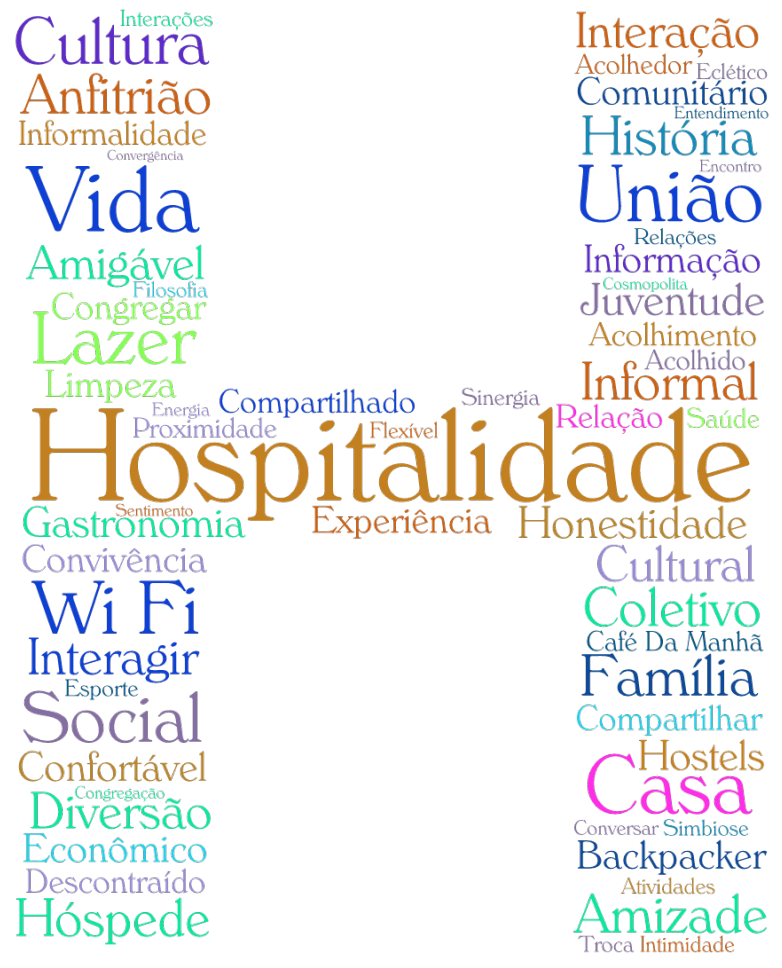

Figura 02 - Logo da essência dos hostels Fonte: Elaborada pelo autor (2015). presença da hospitalidade genuína na formação e na propagação dos albergues da juventude, na Alemanha e, finalmente, no mundo. A filosofia alberguista promove o contato social. Os hostels possuem certa autonomia em relação à indústria hoteleira, conseguindo expor, mais facilmente que os hotéis convencionais, demonstrações de hospitalidade verdadeira, sob o papel do recepcionista, o que é fundamentalmente um anfitrião.

Quanto à gênese desse meio de hospedagem no Brasil, pode-se considerar que a ausência de movimentos sociais no país dificulta a implantação de novos valores, novas realidades que favoreçam as camadas sociais alienadas. Esses segmentos alternativos da sociedade, atrelados aos velhos conceitos em vigência ou a novos impostos pelas classes superiores, ficam marginalizados ou excluídos do foco principal do desenvolvimento social e, em último caso, da corrente principal do turismo. No caso específico dos hostels, vale notar que esse movimento vem ganhando força e, por esse meio de hospedagem, possui um caráter revolucionário e social, esperando-se que num futuro bem próximo possa contar com uma legislação fiel a suas características essenciais.

Na relação dos hostels com o espaço turístico, percebe-se que esses possuem uma relação de conservação por meio da renovação e da reutilização do patrimônio material. Geralmente, quando há algo de efêmero na relação entre visitante e visitado, isto acontece com mais frequência, no chamado turismo de massa e na hotelaria convencional. Se é verdade que poucas pessoas quando em férias ousam se aventurar fora dos rígidos programas estabelecidos pelos pacotes turísticos, cabe à academia esclarecer certos conceitos e disponibilizá-los aos visitantes. Os hostels podem proporcionar ao turista uma aproximação mais humana e verdadeira com a localidade receptora, por meio da hospitalidade e do patrimônio histórico que este ajuda a preservar.

No entanto, no Brasil há certa falta de conhecimento e até preconceito, com este tipo de acomodação. Essa situação se deve ao recente advento dos hostels no país e à ignorância sobre sua filosofia. $O$ processo de industrialização e urbanização foi rápido e agressivo em demasia, em muitos casos a apropriação do território se deu de forma indevida, interferindo no turismo e na conservação do patrimônio cultural. 
De acordo com os hosteleiros, conflitos ocorrem, em sua maioria, quando há um tipo de viajante desinformado, desacostumado ou insatisfeito com a proposta de sociabilidade e coletividade de um hostel. Essas ocorrências acontecem com maior frequência quando $\mathrm{o}$ viajante brasileiro entra em conflito com o estrangeiro. Devido à desinformação do brasileiro quanto à filosofia alberguista e o conceito desse meio de hospedagem, muitos acabam por se hospedar nesse tipo de acomodação esperando um hotel barato, com privacidade e exclusividade. Quando se deparam com a vida em comunidade, expressam sua frustração se isolando do restante do grupo e reclamando da gestão com o hosteleiro.

Diversas limitações de estudo foram observadas. Uma entrevista aplicada a uma amostra mais abrangente é extremamente necessária para a validação dos resultados preliminares aqui obtidos. Durante o estudo novos questionamentos foram levantados, como a questão da contratação do recepcionista. Como se dá esse processo em detalhes? Essa parece ser uma questão extremamente importante, haja vista que essa figura é essencial para a existência desse meio de hospedagem. Outra questão ainda a ser abordada diz respeito a uma melhor caraterização do público-alvo brasileiro e suas próprias opiniões e ideias sobre esse meio de hospedagem. Um estudo voltado especificamente aos backpackers é essencial para o entendimento dos hostels no Brasil.

Diante do exposto, cabe a reflexão: se a hospitalidade é uma dádiva, portanto desinteressada, é legítima a apropriação do termo pelo turismo? Se a resposta que se busca é otimista, então demonstrações dessa verdadeira hospitalidade no turismo são possíveis por meio dos hostels, com maior facilidade do que, talvez, nos tradicionais empreendimentos hoteleiros, considerando-se que os hostels buscam criar elos sociais por meio da sensibilidade para os assuntos coletivos e culturais. Buscam, também, proporcionar uma relação turística mais íntima e humanista, que favorece a aproximação de pessoas, por meio da relação entre ser acolhedor e ser acolhido.

A educação da hospitalidade, em grande parte das instituições de ensino superior, parece ser assimétrica, pois apresenta a hospitalidade como uma qualidade na prestação de serviços turísticos, como se fosse uma rua de mão única, cujo ser acolhedor recebe e "agrada" o ser acolhido. No entanto, a hospitalidade, em sua essência, consiste na troca de experiências entre eles. O princípio de alteridade de Levinas, apesar de ser desconhecido e/ou desconsiderado em grande parte da literatura sobre hospitalidade, revê muito bem as relações hospitaleiras entre ser visitado e ser visitante.

De uma maneira geral, em relação à essência dos hostels, os entrevistados manifestaram o entendimento de que esses meios de hospedagem representam um local de união entre pessoas, entre culturas e de entendimento entre diferentes povos. Um local de troca de experiências, de energia, de sentimentos e sensações, de interação entre pessoas, de experiências de vida. Um ambiente familiar, social e descontraído. Um local de convergência de pessoas, de encontro de histórias, de amizade, cujas pessoas se sentem em casa.

\section{Referências}

Abrantes, J. M. (2014). Hostels e centros históricos das cidades: Envelhecimento ou rejuvenescimento? Hospitality International Journal Tourism and Hospitality International Journal, 3(34), 355-383.

Assunção, P. D. (2012). História do Turismo no Brasil entre os séculos XVI e XX: viagens, espaço e cultura. Barueri: Manoel.

Bahls, Á. A. (2015). Hostel: proposta conceitual, análise socioespacial e do panorama atual em Florianópolis (SC). Dissertação de Mestrado, Turismo e Hotelaria, Universidade do Vale do Itajaí (UNIVALI): Balneário Camboriú, Brasil.

Bahls, Á. A. D. S. M., \& Pereira, R. M. (2017). Quem é quem nos meios de hospedagem alternativa - Parte I: O perfil dos "hosteleiros" de Florianópolis (SCBrasil). Revista ESPACIOS, 38(9), 29.

Bahls, Á. A. D. S. M., \& Pereira, R. M. F. do A. (2017). A Gênese Dos Hostels : comparação entre o panorama internacional e nacional - em busca de um conceito original. In F. A. dos Anjos, N. P. Angeli, \& S. G. dos Anjos (Eds.), Turismo e Megaeventos (pp. 161-192). Itajaí: Univali.

Bahls, Á. A. D. S. M., \& Pereira, R. M. F. do A. (2017). Hostel, Uma Casa Sem Paredes: em busca de uma matriz classificatória de áreas físicas. Applied Tourism, 2(2), 1.

Bahls, Á. A. D. S. M., \& Pereira, Y. C. C. (2018). Hostel: o estado da arte e considerações para futuras pesquisas. Caderno Virtual de Turismo, 17(3).

Bardin, L. (2009). Análise de Conteúdo. Lisboa, Portugal; Edições 70, LDA.

Bauer, M.; Gaskell G. (2002). Pesquisa qualitativa com texto, imagem e som: um manual prático. Petrópolis: Editora Vozes.

Braga, R. (2003). Dicionário de Turismo. São Paulo: Uniletras. 
Bressan, S. J. (2008). Fundamentos das Ciências Sociais. Ijuí: UNIJUÍ.

Camargo, L. O. (2002). Turismo, hotelaria e hospitalidade. In: Dias, C. M. Hospitalidade: reflexões e perspectivas. Barueri: Manole, p. 1-23.

Camargo, L. O. (2004). Hospitalidade. São Paulo: Aleph.

Campos, C. J. (2004). Método de Análise de Conteúdo: ferramenta para a análise de dados qualitativos no campo da saúde. Revista Brasileira de Enfermagem REBEn, 57(5), pp. 611-614.

Campos, J. R. (2005). Introdução ao universo da hospitalidade. Campinas: Papirus.

Castro, C.; Guimarães, V. L.\& Magalhães, A. M. (2013). História do Turismo no Brasil. Rio de Janeiro: FGV.

Coburn, O. (1950). Youth Hostel Story. Londres: The National Council of Social Service.

Costa, H. A., Franco, A. F., \& Hoffmann, V. E. (09 de Outubro de 2013). Cooperação entre pequenas empresas do turismo e competitividade: estudo de hostels no Rio de Janeiro. X Seminário da Associação Nacional Pesquisa e Pós-Graduação em Turismo ANPTUR, pp. 01-20.

Cury, C. J. (1990). Educação e Contradição: elementos metodológicos para uma teoria crítica do fenômeno educativo (4 ed.). São Paulo: Cortez \& Autores Associados.

Customer Alliance. (2017). A Brief History of the Hotel Industry - From the Stone Age into the digital world. Acesso em 14 de março d 2017. Disponível em https://www.customer-alliance.com/en/articles/ hotel-industry/

Dencker, A. d. (2007). Pesquisa em Turismo Planejamento, métodos e técnicas. São Paulo: Futura.

Deslauriers, J-P. (1991). Recherche qualitative: guide pratique. Québec: McGrawHill, Éditeurs.

Deus, J.M.; Delvizio, I.A.; Nascimento, F.B.F. (2016). Levantamento, seleção e sistematização de termos relativos aos meios de hospedagem. Applied Tourism, 1(3), 11-30.

Dias, C. M. (2002). Hospitalidade: Reflexões e Perspectivas (1 ed.). Barueri: Manole.

Engels, F. (2009). The Condition of the Working Class in England. 8. ed. Oxford: Oxford University Press.

Fausto, B. (2013). História do Brasil. São Paulo: Edusp.

Ferreira, F. L. (1975). Dicionário brasileiro de turismo. Rio de Janeiro: Colorama.

Ferri, C. \& Ruschmann, D. V. M. (fev. 2000). Termos gerais em hotelaria. Turismo - Visão e Ação (Glossário), 2(4), 35-51.
Garcia, M. X. (2004). Vocabulário para o Turismo: português/inglês. São Paulo: SBS.

Gerhardt, T. E.; Silveira, D. T. (2009).Métodos de pesquisa. Porto Alegre: Editora da UFRGS.

Giaretta, M. J. (2003). Turismo da Juventude. Barueri: Manole.

Glaser, A. L. (2008). Materialismo cultural (Vols. Tese (doutorado) apresentada à Universidade de São Paulo - Faculdade de Filosofia, Letras e Ciências Sociais). São Paulo: USP.

Goeldner, C. R.; Ritchie, J. R. B.; Mcintosh, R. W. (2002). Turismo - Princípios, Práticas e Filosofias. Porto Alegre: Bookman.

Gotman, A. (2011). L'hospitalité: ducapitaine Cook à l'hôteadministratif. CNRS - Centre de recherchessurleslienssociaux. Sciences-Croisées, Paris, v. 9.

Grassl, A. \& Heath, G. (1982). The Magic Triangle - A short story of the world youth hostel movement. Welwyn Garden City: International Youth Hostel Federation.

Grinover, L. (2002). Hospitalidade: um tema a ser reestudado e pesquisado. In C. M. Dias, Hospitalidade: Reflexões e perspectivas (pp. 25-38). Barueri: Manole.

Halvey, M., \& Keane, M. T. (May de 2007). An Assessment of Tag Presentation Techniques. World Wide Web Conference Committee.

Heath, G. (1962). Richard Schirrmann - The first youth hosteller. Copenhaguem: International Youth Hostel Federation.

Holanda, S. B. (1995). Raízes dos Brasil (26 ed.). São Paulo: Companhia das Letras.

Hostelling International. (2014). About Us. Acesso em 27 de Outubro de 2014, disponível em Hostelling International: https://www.hihostels.com/about-hi/ about-hostelling-international

Hostelworld. (2014). Hostels in Rio de Janeiro, Brazil. Acesso em 20 de Janeiro de 2014, disponível em http://www.hostelworld.com/search?search_keyw ords $=\mathrm{Rio}+\mathrm{de}+\mathrm{Janeiro} \% 2 \mathrm{C}+$ Brazil\&country $=\mathrm{B}$ razil\&city $=$ Rio-de-Janeiro\&date from $=2014-12$ 17\&date to $=2014-12-19$

Kennedy, G. (1998). Children of the Sun. Mecca: Nivaria Press.

Kosik, K. (2002). Dialética do concreto. Rio de Janeiro: Paz e Terra.

Krause, R. W. \& Bahls, Á. A. (2016). Serviços clássicos na restauração comercial: proposta de padronização e esclarecimentos para futuras pesquisas. Revista Brasileira de Pesquisa Em Turismo, v. 10, n. 3, p. 550-573.

Laqueur, W. (1962). Young Germany - A history of the German Youth Movement. New York: Basic Books.

Lashley, C.\& Morrison, A. (2004). Em busca da hospitalidade: perspectivas para um mundo globalizado. 1. ed. Barueri: Manole.

Leal, E. J. (2011). Produção acadêmico-científica: a pesquisa 
e o ensaio. Itajaí, SC, Brasil: Universidade do Vale do Itajaí.

Lefebvre, H. (2009). Dialetical Materialism. Minneapolis: University of Minnesota Press.

Libório, B., \& Oliveira, F. (2014). Hostels ploriferam, mas atraem poucos turistas. Fonte: Folha de São Paulo: http:/wwww1.folha.uol.com.br/ mercado/2014/01/1399416-hostels-proliferammas-atraem-poucos-turistas.shtml

Lohmann, G. \&Panosso Netto, A. (2008). Teoria do Turismo: conceitos, modelos e sistemas. São Paulo: Aleph.

Marconi, M. D. \& Lakatos, E. M. (2003). Fundamentos de Metodologia Científica. São Paulo: Editora Atlas.

Martins, G. d. (2009). Metodologia da investigação científica para ciencias sociais aplicadas. São Paulo: Editora Atlas.

Marx, K., \& Engels, F. (1998). Manifesto of the comunist party. London: Verso.

Minayo, M. C. S. (2001). Pesquisa social: teoria, método e criatividade. Petrópolis: Vozes.

Ministério do Turismo. (08 de Dezembro de 2014). Respostas protocolo 72550000271201453. (Ouvidoria, Editor) Acesso em 08 de Dezembro de 2014, disponível em Gmail: alvarobahls@gmail.com

Ministério do Turismo. (28 de 02 de 2012). Os dez melhores albergues do Brasil. Fonte: Ministério do Turismo: http://www.turismo.gov.br/turismo/ noticias/todas noticias/20120228-1.html

Montandon, A. (2011). O Livo da Hospitalidade: acolhida do estrangeiro na história e nas culturas.São Paulo: SENAC.

Moraes, A. C. R. (2005). Território e história no Brasil. São Paulo: Annablume.

Nash, R., Thyne, M., \& Davies, S. (2006). An investigation into customer satisfaction levels in the budget accommodation sector in Scotland: a case study of backpacker tourists and the Scottish Youth Hostels Association. Tourism Management, pp. 525-532.

Panosso Netto, A. (2010). O que é turismo. São Paulo: Brasiliense.

Pearce, P. L.\& Foster, F. A. (2007). University of Travel: Backpacker learning. Tourism Management, Elsevier, v. 28, p. 1285-1298.

Pinto, Á. V. (1979). Ciência e Existência. Rio de Janeiro: Paz e Terra.

Richardson, R. J. (2008). Pesquisa Social - Métodos e Técnicas (3 ed.). São Paulo: Atlas.

Robaina, R. (2013). Marx e o núcle racional da dálética de Hegel. São Paulo: Alfa-Omega Ltda.
Santos, M. (1979). Espaço e sociedade. Petrópolis: Vozes.

Silva, A. H., \& Fossá, M. I. (2013). Análise de Conteúdo: Exemplo de Aplicação da Técnica para Análise de Dados Qualitativos. IV Encontro de Ensino e Pesquisa em Administração e Contabilidade, pp. 1-14.

Sin, C. H. (2003). Interviewing in 'place': the sociospatial construction of interview data. Area, 35(3), 305-312.

Taniguti, J. H. (2010). Método dialético. Métodos de Pesquisa Social - Psicologia Uniban Morumbi II noturno $-3^{\circ}$ ano. Disponível em: <https://www. scribd.com/document/31446836/Tabela-Metododialetico >. Acesso em: 3 nov. 2017.

The European Consumer Centres' Network. (2009). Classification of hotel stablishments within the EU. Nicosia.

Trigo, L. G. G. (2002). Viagem na Memória: guia histórico das viagens e do turismo no Brasil. São Paulo: SENAC.

Triviños, a. N. (1987). Introdução à Pesquisa em Ciências Sociais. São Paulo: Atlas.

Trotta, J. (1978). Educação e Correlação II - Experiência Internacional e Regional. Os Albergues da Juventude para Jovens e "Jovens de Espírito". Rio de Janeiro: Cia. Brasileira de Artes Gráficas.

UNWTO. (2008). Youth Travel Matters - Understanding the Global Phenomenon of Youth Travel. Marid: United Nations World Tourism Organization.

UNWTO. (2010). AM Reports: The power of youth travel. United Nations World Tourism Organization. Madrid: UNWTO.

Valenzuela, S. T. (2013). Imagens da Hotelaria na cidade de São Paulo - Panorama dos estabelecimentos até os anos 1980. São Paulo: SENAC.

Vieira, E. V. \& Cândido, I. (2003). Glossário Técnico Gastronômico, hoteleiro e turístico. 2. ed. Caxias do Sul: Educs.

VisitScotland. (2012). Guidance Notes for Hostel Operators on Quality Grading. Fonte: VisitScotland.org: http:// www.visitscotland.org/pdf/2012\%20Insert $\% 20$ 1\%20-\%20Hostels.pdf

Volante, J. T. (2011). O segmento low-cost da indústria hoteleira em portugal: o caso dos hostels. Dissertação de Mestrado em Gestão - ISCTE Business School instituo Universitário de Lisboa.

Web Reservations International. (2013). About WRI. Retrieved from Web Reservations International: http://www.webresint.com/about_us.html

Zopiatis, A., \& Constanti, P. (2012). Managing Hospitality Internship Practices: A Conceptual Framework. Journal of Hospitality \& Tourism Education, 24(1), 44-51.

\section{Contribuição dos autores na construção} do artigo: 
BAHLS: Idealizador e aplicador da pesquisa; fundamentação teórica (especificamente sobre os hostels e o contexto turístico); tratamento dos dados obtidos na pesquisa de campo; elaboração, análise e interpretação dos resultados.
PEREIRA: Estruturação do artigo; Fundamentação teórica (especialmente no que diz respeito ao materialismo dialético); interpretação parcial dos resultados. 